Article

\title{
Evaluation of Satellite-Based Rainfall Estimates and Application to Monitor Meteorological Drought for the Upper Blue Nile Basin, Ethiopia
}

\author{
Yared Bayissa ${ }^{1,2, *}$ (D) , Tsegaye Tadesse ${ }^{1}$, Getachew Demisse ${ }^{1}$ and Andualem Shiferaw ${ }^{1}$ \\ 1 National Drought Mitigation Center, University of Nebraska-Lincoln, Lincoln, CA 68583, USA; \\ ttadesse2@unl.edu (T.T.); gdemisse2@unl.edu (G.D.); andus@huskers.unl.edu (A.S.) \\ 2 IHE Delft Institute for Water Education, Westvest 7, 2611 AX Delft, The Netherlands \\ * Correspondence: yared2002@gmail.com or ybayissa2@unl.edu; Tel.: +1-402-601-0435 \\ Academic Editors: Yang Hong, Yixin Wen and Prasad S. Thenkabail \\ Received: 19 June 2017; Accepted: 25 June 2017; Published: 29 June 2017
}

\begin{abstract}
Drought is a recurring phenomenon in Ethiopia that significantly impacts the socioeconomic sector and various components of the environment. The overarching goal of this study is to assess the spatial and temporal patterns of meteorological drought using a satellite-derived rainfall product for the Upper Blue Nile Basin (UBN). The satellite rainfall product used in this study was selected through evaluation of five high-resolution products (Climate Hazards Group InfraRed Precipitation with Stations (CHIRPS) v2.0, Precipitation Estimation from Remotely Sensed Information using Artificial Neural Networks (PERSIANN), African Rainfall Climatology and Time-series (TARCAT) v2.0, Tropical Rainfall Measuring Mission (TRMM) and Africa Rainfall Estimate Climatology version 2 [ARC 2.0]). The statistical performance measuring techniques (i.e., Pearson correlation coefficient (r), mean error (ME), root mean square error (RMSE), and Bias) were used to evaluate the satellite rainfall products with the corresponding ground observation data at ten independent weather stations. The evaluation was carried out for 1998-2015 at dekadal, monthly, and seasonal time scales. The evaluation results of these satellite-derived rainfall products show there is a good agreement $(r>0.7)$ of CHIRPS and TARCAT rainfall products with ground observations in majority of the weather stations for all time steps. TARCAT showed a greater correlation coefficient $(r>0.70)$ in seven weather stations at a dekadal time scale whereas CHIRPS showed a greater correlation coefficient $(r>0.84)$ in nine weather stations at a monthly time scale. An excellent score of Bias (close to one) and mean error was observed in CHIRPS at dekadal, monthly and seasonal time scales in a majority of the stations. TARCAT performed well next to CHIRPS whereas PERSSIAN presented a weak performance under all the criteria. Thus, the CHIRPS rainfall product was selected and used to assess the spatial and temporal variability of meteorological drought in this study. The 3-month Z-Score values were calculated for each grid and used to assess the spatial and temporal patterns of drought. The result shows that the known historic drought years (2014-2015, 2009-2010, 1994-1995 and 1983-1984) were successfully indicated. Moreover, severe drought conditions were observed in the drought prone parts of the basin (i.e., central, eastern and southeastern). Hence, the CHIRPS rainfall product can be used as an alternative source of information in developing the grid-based drought monitoring tools for the basin that could help in developing early warning systems.
\end{abstract}

Keywords: drought assessment; CHIRPS; satellite rainfall; evaluation; Upper Blue Nile Basin

\section{Introduction}

Drought is one of the most costly weather extremes that occurs in different parts of the world every year. It affects many sectors, causes large economic losses and threatens human life and the 
environment [1-4]. Ethiopia has been impacted by recurrent and prolonged drought events that have affected a large proportion of the population, destroyed crops and killed livestock. Severe historic drought events have occurred in the country in the past few decades [5,6]. Some of the notable droughts (such as those in 2014-2015, 2009-2010, 1994-1995 and 1983-1984) covered the majority of the country [5-8]. Based on data obtained from Centre for Research on the Epidemiology of Disasters (CRED) (http:/ / www.emdat.be/database, accessed on March 2017), the 1983-1984 drought was one of the most severe drought years, with $22 \%$ of the total population ( 35 million) affected [9]. Drought affects the agricultural sector, which relies on adequate and timely seasonal rainfall. More than $85 \%$ of the population in Ethiopia depend on income generated from agricultural products [10]. However, agricultural practices are very primitive and predominantly rain-fed [11]. In addition, the high variability of rainfall in both space and time leads to high variability of the available water at the root zone $[12,13]$. Drought monitoring and early warning systems are crucial to mitigate drought's adverse impacts in the country [8].

In general, drought monitoring includes the wide application of drought indices that measure the deficit of hydrologic cycle components, as compared to the long-term mean [14,15]. The long-term mean is used as a reference to measure the deviation of a particular event. Accordingly, meteorological drought is defined based on the degree of dryness or deviation from normal or average amount of rainfall for a prolonged period [16]. The deficit in meteorological parameters (mainly rainfall) can be considered as a precursor for the deficit of other hydrological water cycle components (river flow, ground water flow, reservoir storage, etc.), known as hydrological drought. The deficit of readily available water for plants to use to satisfy water demand is often defined as agricultural drought [17-19]. Meteorological drought can be considered as an early indication of drought before it affects the agricultural and hydrological water components [20]. The meteorological drought monitoring system depends on the availability of rainfall data at adequate spatial and temporal scales. However, getting a reliable climatic record of rainfall amounts at weather observing stations that are evenly distributed over the area is one of the main challenges, particularly in developing countries such as Ethiopia [21,22]. To address these challenges, satellite-based rainfall estimates/products are becoming increasingly available for use at global and regional scales. The main advantage of the remote sensing based rainfall products is that they are reasonably good in terms of spatial and temporal coverage and have proved their applicability to climate and hydrological studies [23,24]. However, their accuracy has to be evaluated and compared with ground truth rainfall measurement before using it for further application in drought and other natural hazards studies [25-27].

Several studies have attempted to compare and evaluate satellite rainfall products with ground observations across many watersheds. For example, evaluation of the satellite rainfall products was undertaken through hydrologic simulation in semi-distributed (Soil and Water assessment tool-SWAT) [27] and fully distributed (MIKESHI) hydrologic models [28] in small watersheds in the Upper Blue Nile Basin. Hydrological models use many input parameters together with rainfall to represent the complex nature of the hydrological processes in a given catchment and hence the contribution of rainfall might sometimes be dominated by other input parameters (e.g., land use change, water holding capacity). Other studies have evaluated satellite rainfall products such as the Climate Prediction Center's morphing technique (CMORPH), the Tropical Rainfall Measuring Mission (TRMM), the Multi-satellite Precipitation Analysis (TMPA) near-real-time product (3B42RT), and the TMPA method post-real-time research version product $(3 B 42)$ in the UBN basin $[23,25,26,29,30]$. Seven satellite rainfall products-Africa Rainfall Estimate Climatology (ARC 2.0), Climate Hazards Group InfraRed Precipitation with Stations (CHIRPS), Precipitation Estimation from Remotely Sensed Information using Artificial Neural Networks (PERSIANN), African Rainfall Estimation (RFE 2.0), Tropical Applications of Meteorology using SATellite (TAMSAT), African Rainfall Climatology and Time-series (TARCAT), and Multi-satellite Precipitation Analysis (TMPA)—were evaluated and compared with ground weather station data for Burkina Faso, West Africa [31]. The study indicated that RFE performed best and TARCAT was the weakest [31]. Similar studies (e.g., study [32]) carried 
out for Mozambique showed TARCAT outperforming based on the majority of statistical measures of skill. However, limited studies have been conducted on assessing the applicability of satellite rainfall for meteorological drought monitoring, particularly for the UBN basin in Ethiopia.

These satellite products have long-term recorded data, which is an advantage for drought study. Moreover, they represent and capture the spatial variability of rainfall, which is useful for studying the spatial patterns of drought in the UBN basin. This study focus on the spatial and temporal assessment of meteorological drought in the Ethiopian highlands (UBN basin) using better satellite rainfall products. For this purpose, five satellite rainfall products (ARC 2.0, CHIRPS, PERSIANN, TARCAT, and TMPA) were first evaluated with respect to weather station data to identify and recommend the best satellite-derived rainfall product for drought monitoring in the basin.

\section{Study Area}

The Ethiopian part of the UBN, also known as the Abbay Basin, is located in the northwestern region of the country between $7^{\circ} 40^{\prime} \mathrm{N}$ and $12^{\circ} 51^{\prime} \mathrm{N}$ latitudes and $34^{\circ} 25^{\prime} \mathrm{E}$ and $39^{\circ} 49^{\prime} \mathrm{E}$ longitudes (Figure 1). The UBN basin ranks as the largest river basin of the country by its volume of discharge and the second largest by its area [33]. It is also the largest tributary of the Nile River (60\% of the Nile total flow), covering a total drainage area of $176,000 \mathrm{~km}^{2}$ [34]. The UBN basin is the most important water resource for Ethiopia, Sudan and Egypt. Lake Tana, the largest lake in Ethiopia (about $3000 \mathrm{~km}^{2}$ ) is located in the north part of the basin. The topography of the UBN basin signifies two distinct features: the highlands with rugged mountainous areas in the central and eastern part of the basin, and the lowlands in the western part of the basin. The altitude in the basin ranges from $492 \mathrm{~m}$ in the lowlands to $4261 \mathrm{~m}$ in the highlands. While the highlands are the main source of water, the lowlands have expanses of flat lands through which the accumulated flows travel from the highlands to the lower riparian countries (i.e., Sudan and Egypt). The annual rainfall ranges from 787 to $2200 \mathrm{~mm}$, with the highlands having the highest rainfall (ranging from 1500 to $2200 \mathrm{~mm}$ ) and the lowlands receiving less than $1500 \mathrm{~mm}$ [33-35]. The basin experiences bimodal rainfall seasons locally called Belg and Kiremit. Belg is a short rainfall season from March to May whereas Kiremit is the main rainfall season, from June to September, and its failure often causes drought and resulting famine in the basin $[33,36]$.

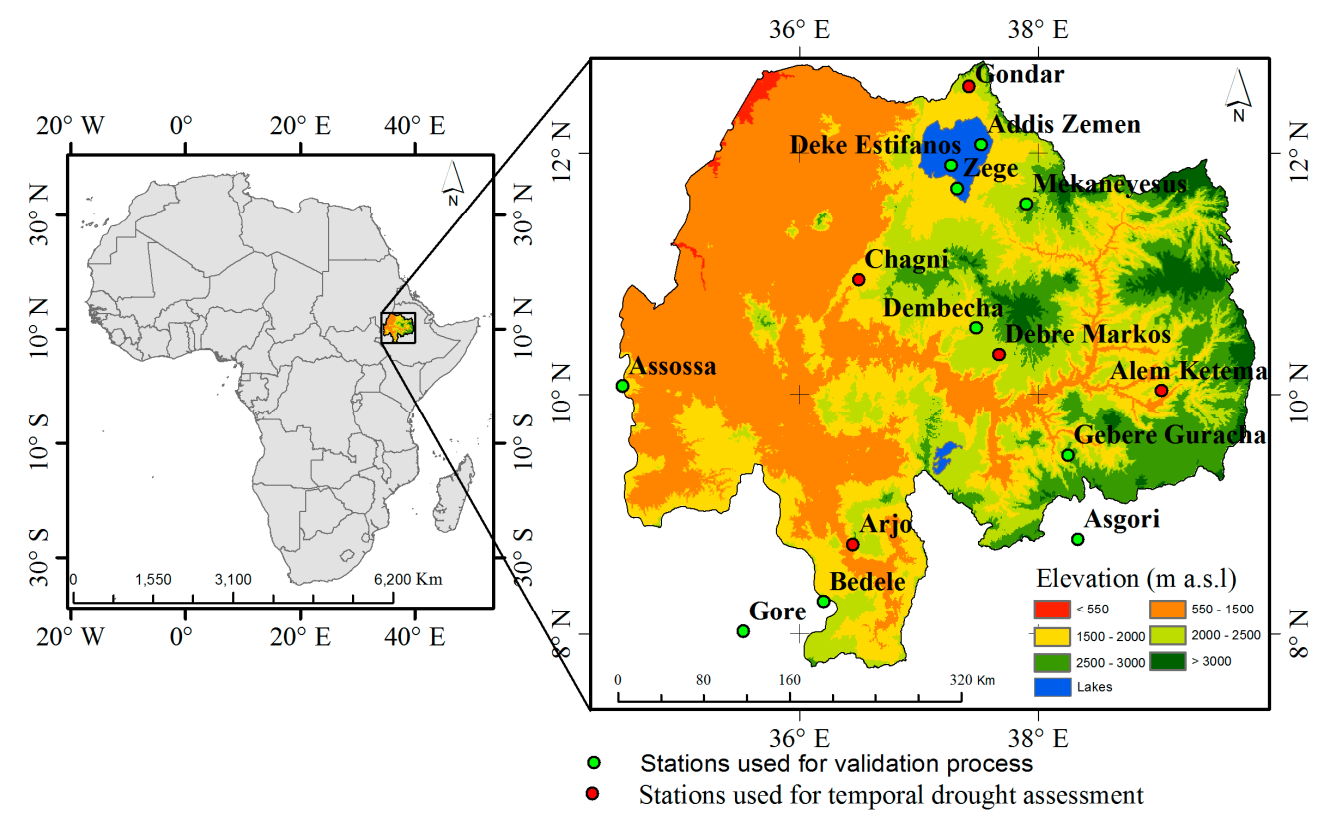

Figure 1. The location of the Upper Blue Nile (UBN) basin. The red circles denote the location of the weather stations used to study the temporal assessment of drought and the green circles show the location of the independent weather stations used for validation of satellite rainfall product. 


\section{Data Used}

\subsection{Weather Station Data}

The observed daily rainfall data from 1998 to 2015 for 23 independent weather stations were obtained from the Ethiopian National Meteorological Agency (NMA). The quality of the data was checked [8] and stations having more than 20\% missing data were discarded from use. Accordingly, 10 independent stations (Figure 1, denoted by green circles) representing different agro-climatic zones were selected and used in this study. Dekadal, monthly, and seasonal data were calculated from the daily rainfall records for each weather station. The historical record of the observed rainfall data varies from station to station. Thus, these 10 weather stations (denoted by green circles in Figure 1) were used for validation of the satellite rainfall products.

\subsection{Satellite Data}

Brief descriptions of the five satellite-derived rainfall products that were selected for evaluation in this study are given in Table 1. These products were selected because of the availability of long time series of data in near-real time, relatively high spatial and temporal resolutions, and free access to the data. Short descriptions of these data are given below.

i. CHIRPS was developed by the U.S. Geological Survey (USGS) and the Climate Hazards Group at the University of California, Santa Barbara (UCSB). CHIRPS is a blended product combining a pentadal precipitation climatology, quasi-global geostationary TIR satellite observations from the CPC and the National Climate Forecast System version 2 (CFSv2) [37] and in situ precipitation observations [38].

ii. TARCAT v2.0 was produced by TAMSAT using archived Meteosat thermal infrared imagery, calibrated against weather station records $[39,40]$.

iii. ARC incorporates geostationary IR, polar orbiting microwave SSM/I and AMSU-B satellite data and gauge data. ARC uses 3-hourly geostationary IR data centered over Africa from the European Organization for the Exploitation of Meteorological Satellites (EUMETSAT) and quality-controlled GTS gauge observations reporting 24-h rainfall accumulations over Africa [41].

iv. PERSIANN, developed by the Center for Hydrometeorology and Remote Sensing (CHRS) at the University of California, Irvine (UCI) [42], uses neural network function classification/approximation procedures to compute an estimate of rainfall rate at each $0.25^{\circ} \times 0.25^{\circ}$ pixel of the infrared brightness temperature image provided by geostationary satellites. An adaptive training feature facilitates updating of the network parameters whenever independent estimates of rainfall are available. The PERSIANN system was based on geostationary infrared imagery and later extended to include the use of both infrared and daytime visible imagery [29,43-47].

v. The TRMM is a joint space mission between NASA and the Japan Aerospace Exploration Agency (JAXA) designed to monitor and study tropical and subtropical precipitation and the associated release of energy. The most widely used outputs are the TMPA 3-hourly (TRMM 3B42) accumulated to daily, and monthly (TRMM3B43) products [39]. The TMPA depends on input from a variety of sensors and sources: the TRMM Precipitation Radar (PR); the TRMM Microwave Imager (TMI); the Advanced Microwave Scanning Radiometer for the Earth Observing System (AMSR-E) on Aqua; the SSM/I and the Special Sensor Microwave Imager/Sounder (SSMIS), both on the Defense Meteorological Satellite Program (DMSP); the AMSU-B and the Microwave Humidity Sounder (MHS), both on the NOAA satellite series; the IR data collected by the international constellation of geosynchronous earth orbit (GEO) satellites; and the GPCP precipitation gauge analysis from the Global Precipitation Climatology Centre (GPCC). Some of these sensors are no longer functional [48]. The Global Precipitation 
Measurement (GPM) mission is built up on the success of TRMM. GPM advances over TRMM on its extended capability to measure light rain, solid precipitation and the microphysical propertied of precipitation particles [39]. The TRMM 3B42 V7 product (TMPA) have been used in this study.

Table 1. Summary of the five satellite products used in this study.

\begin{tabular}{cccc}
\hline Satellite Rainfall Product & Temporal Coverage & Spatial Resolution & Temporal Resolution \\
\hline CHIRPS Version $2.0^{1}$ & 1981-present & $0.05(\sim 5 \mathrm{~km})$ & Daily \\
TARCAT Version $2.0^{2}$ & 1983-present & $0.0375^{\circ}(\sim 4 \mathrm{~km})$ & Dekadal \\
ARC Version $2.0^{3}$ & 1983-present & $0.1^{\circ}(\sim 10 \mathrm{~km})$ & Daily \\
PERSIANN-CDR 4 & 1983-present & $0.25^{\circ}(\sim 27 \mathrm{~km})$ & Daily \\
TMPA 3B42 Version $7.0^{5}$ & 1998-present & $0.25^{\circ}(\sim 27 \mathrm{~km})$ & 3-hourly \\
\hline
\end{tabular}

Source: ${ }^{1}[38],{ }^{2}[39,40],{ }^{3}[41],{ }^{4}[47],{ }^{5}[48]$.

\section{Method}

\subsection{Evaluation of Satellite-Derived Rainfall}

In this study, the evaluation of the satellite rainfall products has been carried out for the period from 1998 to 2015 using measured rainfall data from ten independent weather stations in the Ethiopia highlands. The majority of the satellite rainfall products blend the ground-based weather stations data to enhance its accuracy and reliability. Hence, evaluation with independent data set is crucial in the study region to identify the satellite product that reproduces the measured data relatively well. There are more than 94 operational weather stations in the study region; however, most of them are used in the blending process in the majority of satellite rainfall products. The selection of the independent weather stations also accounted the relative location of each station in different agro-climatic zone and availability of good records during the study period. Next, the grid values of the satellite rainfall estimates are compared to the ground-based observations regardless of the positions of the weather stations within the grid box. This means, point-to-grid comparison is followed in this study irrespective of the different grid size of each satellite product. Some differences might be expected in point-to-pixel comparison given the different spatial and temporal uncertainties [25,27]. The evaluations of the satellite rainfall products were conducted at dekadal, monthly and seasonal time scales through accumulating the daily rainfall data. For example, the dekadal (10-day) data of the weather stations were calculated using the daily accumulation of rainfall for each station. Similar approaches were applied for TRMM data, as the original data were obtained at a finer temporal scale ( $3 \mathrm{~h}$ ). In each month, the first two dekads comprise 10 days and the third dekad comprises 8-11 days, depending on the month.

\subsection{Evaluation Statistics}

The pairwise comparison statistics techniques such as Pearson correlation coefficient (r), Mean Error (ME), Root Mean Square Error (RMSE) and Bias were used to evaluate the satellite estimates of rainfall. These techniques are commonly used in many research efforts $[25,27]$.

The Pearson correlation coefficient ( $r$ ) is used to measure the goodness of fit and linear association between two variables. It measures how well the satellite rainfall product corresponds to the observed rainfall; see Equation (1). Its value ranges between 0 to 1 in which one indicates the perfect score.

$$
\mathrm{r}=\frac{\sum(\mathrm{O}-\overline{\mathrm{O}})(\mathrm{S}-\overline{\mathrm{S}})}{\sqrt{\sum(\mathrm{O}-\overline{\mathrm{O}})^{2}} \sqrt{\sum(\mathrm{S}-\overline{\mathrm{S}})^{2}}}
$$


where $\mathrm{r}$ is the correlation coefficient, $\mathrm{O}=$ gauge rainfall measurement, $\overline{\mathrm{O}}=$ average gauge rainfall measurement, $S=$ satellite rainfall estimate, $\bar{S}=$ average satellite rainfall estimate, and $n=$ number of data pairs.

ME estimated the average error (Equation (2)); a positive value indicates an overestimate of the satellite rainfall whereas a negative value indicates an underestimate as compared to the observed rainfall. ME values of zero is the perfect score.

$$
\mathrm{ME}=\frac{1}{\mathrm{n}} \sum(\mathrm{S}-\mathrm{O})
$$

where $\mathrm{ME}$ is the mean error, $\mathrm{O}=$ gauge rainfall measurement, and $\mathrm{S}=$ satellite rainfall estimate.

The RMSE is used to measure the average magnitude of the estimated errors between the satellite rainfall and the observed rainfall; see Equation (3). A lower RMSE value means greater central tendencies and small extreme error. RMSE value of zero is the perfect score.

$$
\mathrm{RMSE}=\sqrt{\frac{1}{n} \sum(\mathrm{S}-\mathrm{O})^{2}}
$$

where RMSE is the root mean square error, $\mathrm{O}=$ gauge rainfall measurement, and $\mathrm{S}=$ satellite rainfall estimate.

Bias reflects how well the mean of the satellite rainfall corresponds with the mean of the observed rainfall; see Equation (4). A Bias value closer to one indicates the cumulative satellite rainfall estimate is closer to the cumulative observed rainfall. Bais value of one is the perfect score.

$$
\text { Bias }=\frac{\sum \mathrm{S}}{\sum \mathrm{O}}
$$

where $\mathrm{O}=$ gauge rainfall measurement, and $\mathrm{S}=$ satellite rainfall estimate.

\subsection{Spatio-Temporal Assessment of Meteorological Drought}

In this study, five satellite rainfall products were evaluated to identify the best product to use for further application in dealing with water-resource-related problems such as drought. The long-term record (1983-2015) of the best performing satellite rainfall product was used to study the spatial and temporal extent and pattern of meteorological drought in the basin. The monthly time series data was the base to calculate the 3-month Z-Score values for each grid using Equation (5). The 3-month Z-Score is often used to characterize the shortfall of rainfall during the rainfall season and its consequence for the reduction of crop yield [14]. The Z-Score approach is similar to the Standardized Precipitation Index (SPI), a commonly used meteorological drought index, although its assumption of rainfall being normally distributed might not be valid all the time. Z-Score is used in this study because of its wide application in meteorological drought studies. Unlike other widely used meteorological drought indices (e.g., Palmer Drought Severity Index (PDSI), and Standardized Precipitation Evapotranspiration Index (SPEI)), Z-Score only uses rainfall data to characterize drought. The drought severity of the 3-month Z-Score was categorized based on McKee's [49] classification, as shown in Table 2. The time series values of the 3-month Z-Score at the corresponding locations of the representative stations (Figure 1, denoted by red circles) were extracted and analyzed to study the frequency, severity and duration of the meteorological drought. The performance of the Z-Score was evaluated on how well it characterized the known historic drought years (2014-2015, 2009-2010, 1994-1995 and 1983-1984). The outcome of this study was compared with previous studies that often used 3-month SPI for drought assessment $[8,50]$.

$$
\text { Z-Score }=(X-\mu) / \sigma,
$$

where, $X$ is the value of the particular event; $\mu$ is the long term mean; $\sigma$ is the long-term standard deviation. 
The spatial assessment of the meteorological drought for the main rainfall season (Kiremit) was produced for 1983-2015. The extent of the droughts during the known historic drought years were assessed, and two recent drought years (2009 and 2015) and one wet year (2006) were selected for further discussion in this study.

Table 2. SPI values to categorize drought.

\begin{tabular}{cc}
\hline SPI Values & Drought Category \\
\hline-2.00 and less & Extreme drought \\
-1.50 to -1.99 & Severe drought \\
-1.00 to -1.49 & Moderate drought \\
0 to -0.99 & Near normal or mild drought \\
Above 0 & No drought \\
\hline
\end{tabular}

\section{Results and Discussion}

\subsection{Evaluation of Satellite Rainfall}

In this study, five satellite rainfall products were investigated to identify the best product to use for spatial and temporal assessment of meteorological drought at dekadal, monthly and seasonal time scales. The evaluation was carried out using data for the period from 1998 to 2015. A daily comparison was not carried out because of the weak performance reported in previous studies on other watersheds/basins [31,32].

\subsubsection{Dekadal Comparison}

Figure 2 shows the plots of statistical indicators obtained for weather stations against the different satellite estimates. In general, the result shows a good agreement between the weather stations and satellite estimates, with the correlation coefficient values ranging from 0.5 to 0.89 . Relatively, higher correlation coefficients were obtained when CHIRPS (0.88 to 0.69) and TARCAT (0.89 to $0.70)$ were correlated with data from the weather stations. The lowest correlation coefficient $(0.5)$ was obtained when TMPA rainfall were correlated with the measured rainfall weather data at the Dek Istifanos weather station (Figure 2a). A mean Bias relatively close to one was scored by CHIRPS (0.97) and TMPA (0.95) more often than other products. This shows there is a good agreement between the cumulative values of CHIRPS and TMPA rainfall estimates and the cumulative value of each weather station. PERSIANN showed high mean Bias (0.6) and hence the cumulative values were underestimated. The cumulative values of PERSIANN, ARC and TARCAT rainfall were underestimated in all stations except Assossa, whereas CHIRPS and TMPA overestimated the cumulative values in half of the total number of weather stations (Figure 2b). In addition, CHIRPS showed low ME (average $-3.01 \mathrm{~mm} \mathrm{dekad}^{-1}$ ) and RMSE (average $30.63 \mathrm{~mm} \mathrm{dekad}^{-1}$ ) relatively close to zero, whereas PERSIANN showed higher values (average $41.50 \mathrm{~mm} \mathrm{dekad}^{-1}$ ) deviating from zero.

Figure 3 shows the scatter plots produced between the point-based dekadal data of the weather stations versus the five satellite-based rainfall estimates. A relatively higher coefficient of determination values $\left(R^{2}=0.7\right)$ was observed for CHIRPS and TARCAT rainfall estimates whereas a lower value $\left(R^{2}=0.48\right)$ was observed in the TMPA rainfall estimate. The trend line of CHIRPS rainfall is converging to the $45^{\circ}$ line, which shows the existence of a good agreement between CHIRPS rainfall and gauge rainfall whereas PERSIANN is relatively diverging from the $45^{\circ}$ line. 

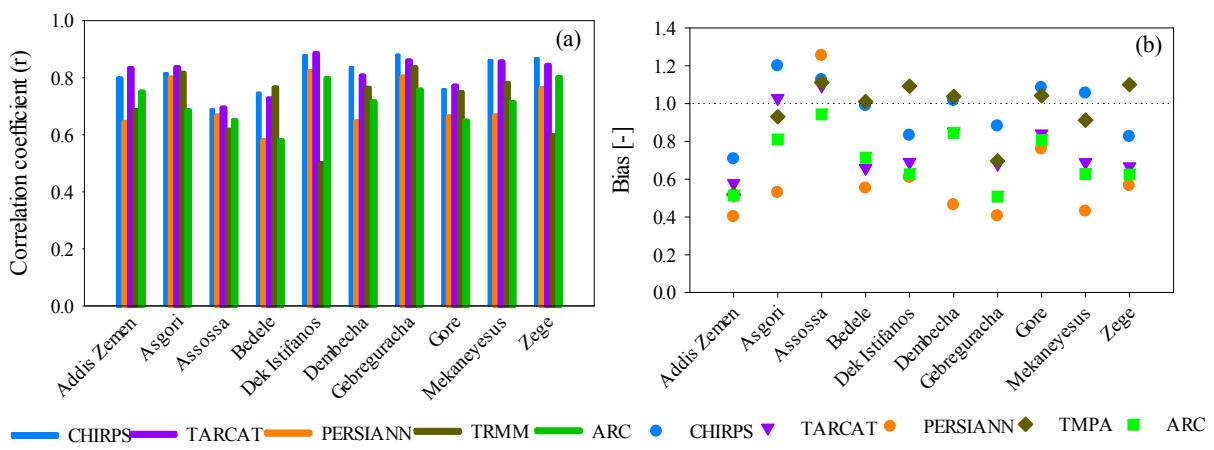

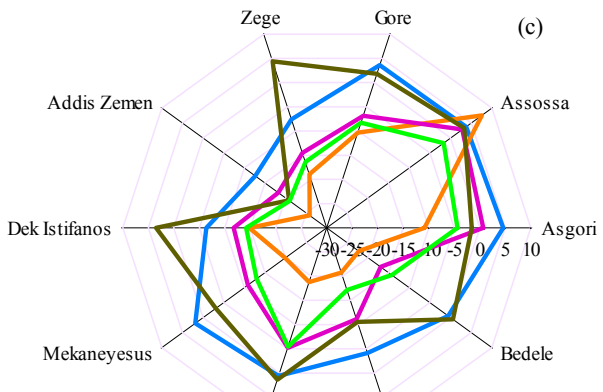

Dembecha Gebreguracha

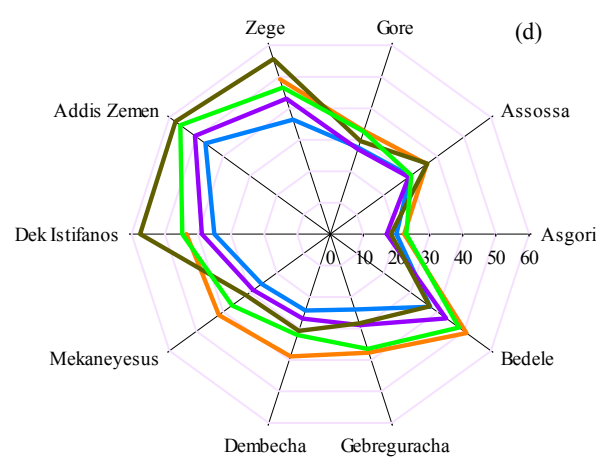

TMPA $\longrightarrow$ ARC

Figure 2. The statistical indicators-correlation coefficient (a), Bias (b), mean error (c) and root mean square error (d) - for each station at dekadal time scale.
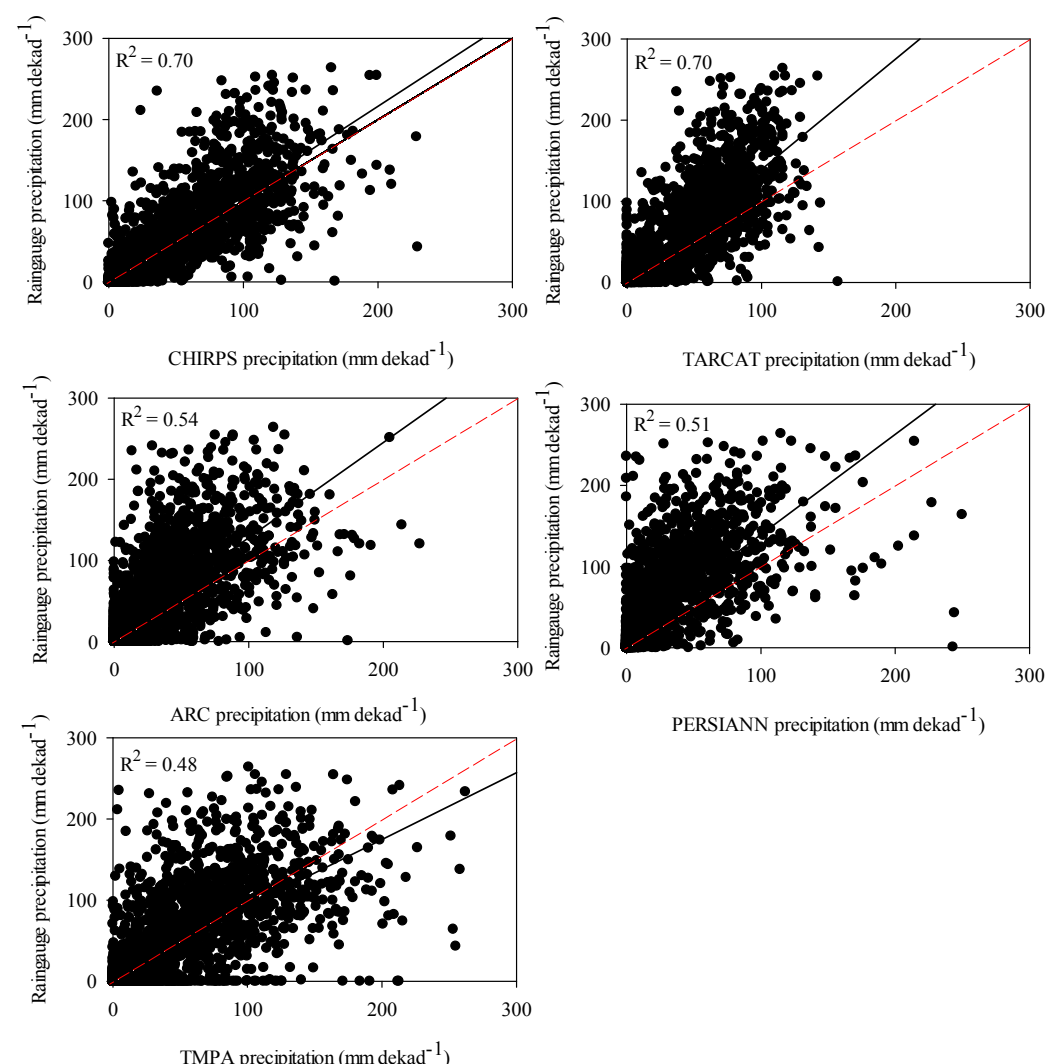

PERSIANN precipitation $\left(\mathrm{mm} \mathrm{dekad}^{-1}\right)$

Figure 3. Scatter plots between the raingauge versus the five satellite-based rainfall estimates at dekadal time scales. 


\subsubsection{Monthly Comparison}

The monthly comparison of the satellite-derived rainfall with the weather stations was carried out using statistical approaches similar to those noted in Section 5.1.1 for the dekadal time scale. The comparison was carried out using an independent rainfall dataset obtained from the ten weather stations shown in Figure 1. In general, good agreement between the five satellite-based rainfall estimates and the weather station-based rainfall observations was found using Pearson's correlation coefficient (r), ranging from 0.54 to 0.95 (Figure 4a). CHIRPS scored the maximum $r(0.95)$ at Gebreguracha station; the minimum was scored by ARC $(\mathrm{r}=0.54)$ at Agaro station (Figure 4a). Overall, CHIRPS correlated very well, with correlation coefficient $(\mathrm{r})$ values ranging from 0.82 to 0.95 compared to the other satellite rainfall products in all weather stations except Bedele, which scored the second highest correlation coefficient value $(\mathrm{r}=0.82)$. Next to CHIRPS, TARCAT scored the next highest correlation coefficient values (ranging from 0.75 to 0.93). In addition, CHIRPS and TMPA showed mean Bias scores of 0.98 and 0.94, respectively, which are close to the perfect score of 1.00 (Figure 4b). PERSIANN scored the weakest mean Bias of 0.6 whereas ARC and TARCAT scored better than PERSIANN ( 0.71 and 0.79 respectively) but relatively weaker than CHIRPS and TMPA. In other words, cumulative estimates of CHIRPS and TMPA were close to the observed rainfall in $80 \%$ of the total validation weather stations whereas PERSIANN and ARC underestimated in all gauging stations. TARCAT showed closer cumulative results in $20 \%$ of the weather stations. TARCAT scored the best ME ( $0.55 \mathrm{~mm}$ month $\left.^{-1}\right)$ and RMSE $\left(17.07 \mathrm{~mm} \mathrm{month}^{-1}\right)$ values at Assossa and Asgori stations, respectively. However, CHIRPS scored the best ME and RMSE in $50 \%$ and $80 \%$ of the total validation weather stations, respectively (Figure 4c,d).
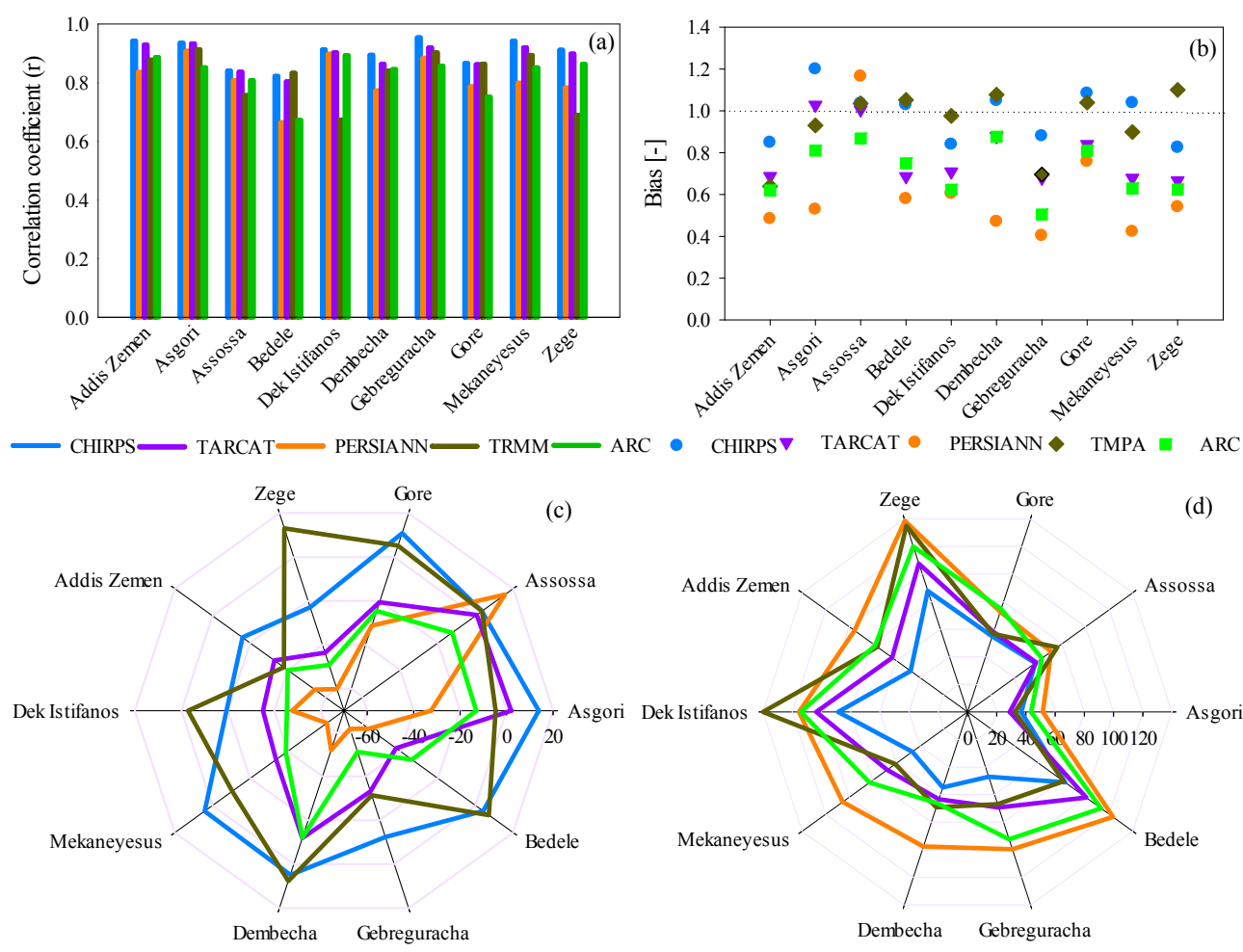

CHIRPS $\longrightarrow$ TARCAT PERSIANN $\longrightarrow$ TMPA - ARC

Figure 4. The statistical indicators such as correlation coefficient (a), Bias (b), mean error (c) and root mean square error $(\mathbf{d})$ for each station at a monthly time scale.

The scatter plots in Figure 5 were also produced using the monthly time series data of all the stations against the satellite-based rainfall products that were extracted at the corresponding locations 
of the weather stations. The highest coefficient $\left(R^{2}=0.86\right)$ was scored by CHIRPS. TARCAT scores the next highest $\left(R^{2}=0.83\right)$ whereas TMPA scores the lowest $\left(R^{2}=0.68\right)$. However, the trend lines of CHIRPS and TMPA follow the $45^{\circ}$ line that showed similarity in variability with the gauged rainfall.
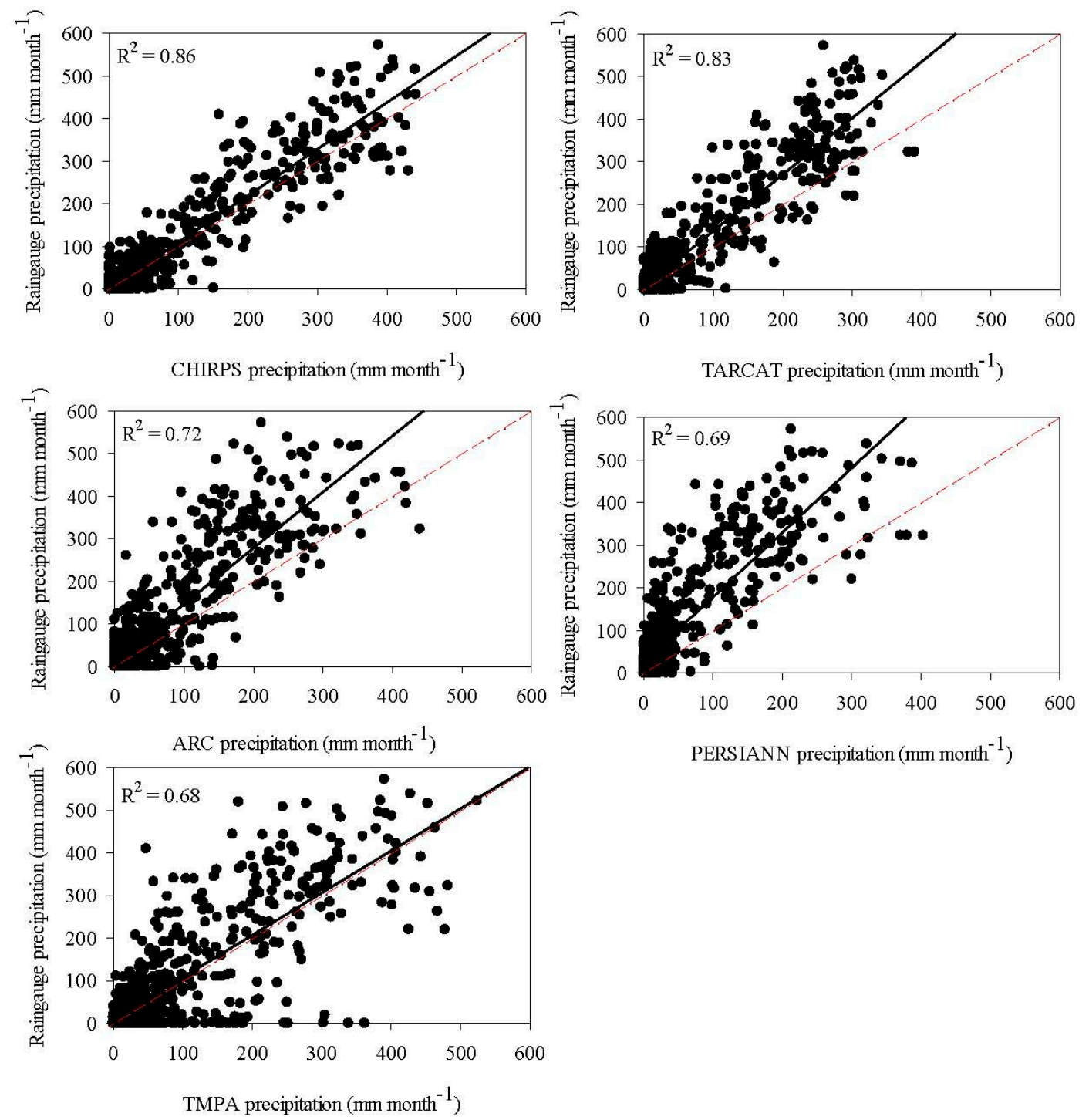

PERSIANN precipitation $\left(\mathrm{mm}\right.$ month $^{-1}$ )

Figure 5. Scatter plots between the weather stations versus the five satellite-based rainfall estimates at a monthly time scale.

\subsubsection{Seasonal Comparison}

The failure of the main seasonal rainfall most often causes devastation in the basin since agricultural practices are fully dependent on the seasonal rainfall. The main rainy season in the UBN basin is from June to September. The satellite precipitation estimates were also analyzed at a seasonal time scale. The monthly precipitation data from June to September were added to estimate the seasonal total precipitation for each weather station and each satellite-derived rainfall product (at grid points corresponding to the ten stations). This resulted in 180 seasonal time series data (pairs) over the ten weather stations for each satellite product. Table 3 summarizes the statistical indicators derived using the seasonal time series data. In general, there is good agreement between the satellite products and gauging stations, with correlation coefficients $(\mathrm{r})$ ranging from 0.64 to 0.79 . The maximum correlation coefficient $(r=0.79)$ was obtained with CHIRPS, whereas PERSIANN 
showed the minimum correlation coefficient $(\mathrm{r}=0.64)$. All the satellite rainfall products underestimated seasonal rainfall amounts as compared to the observed rainfall (Bias < 1). Generally, CHIRPS performance is relatively good because minimum mean error $\left(\mathrm{ME}=-27.93 \mathrm{~mm}\right.$ season $\left.^{-1}\right)$ and root mean square error $\left(\mathrm{RMSE}=93.27 \mathrm{~mm}\right.$ season $^{-1}$ ) were scored at the seasonal scale. In addition, the Bias scored by CHIRPS is close to the perfect score of one (Bias $=0.88$ ) as compared to the other satellite-derived products. Again, PERSIANN performed the least (Bias = 0.59) at the seasonal scale. 1.

Table 3. Summary of the seasonal statistical indicators.

\begin{tabular}{ccccc}
\hline Data Set & r & ME & Bias & RMSE \\
\hline CHIRPS & 0.79 & -27.93 & 0.88 & 93.27 \\
PERSIANN & 0.64 & -95.21 & 0.59 & 145.05 \\
TARCAT & 0.73 & -73.04 & 0.69 & 122.79 \\
TMPA & 0.71 & -34.34 & 0.85 & 108.61 \\
ARC & 0.73 & -91.52 & 0.61 & 134.77 \\
\hline
\end{tabular}

In this study, the satellite rainfall products at three time scales (i.e., dekadal, monthly, and seasonal) were analyzed to identify satellite-derived rainfall data that could potentially be used for meteorological drought assessment in the UBN basin. Overall, the performance of the five rainfall-based satellite products (i.e., CHIRPS, TARCAT, TMPA, PERSIANN and ARC) over the UBN basin is promising for further application in drought years. The result of comparative evaluation of these five satellite products showed that CHIRPS is the best satellite-derived rainfall data at dekadal, monthly, and seasonal time scales. Thus, CHIRPS was selected in this study for further application in the spatial and temporal assessment of meteorological drought in the UBN basin.

\subsection{Spatio-Temporal Assessment of Meteorological Drought}

The spatial and temporal assessment of meteorological drought was previously studied for the basin (e.g., study [8]) using rainfall data from 34 meteorological stations. However, relatively few meteorological stations were used to represent the total area of the UBN basin $\left(\sim 176,000 \mathrm{~km}^{2}\right)$. In addition, the weather stations were not evenly distributed over the area, which might affect the quality of the spatial drought assessment. The remote-sensing-based estimates of rainfall are assumed to improve the spatial representation, particularly in areas where the number of weather stations is limited. Hence, the CHIRPS rainfall estimates were used in the subsequent sections to study the spatial and temporal assessment of meteorological drought in the basin for the period from 1983 to 2015.

\subsubsection{Temporal Drought Assessment}

Figure 6 illustrates the time series plots of the 3-month CHIRPS Z-Score at the six selected representative weather stations (i.e., Debremarkos, Gondar, Arjo, Chagni, Alemketema and Assossa) for the period 1983 to 2015 during Kiremit season. The result shows the occurrence of moderate to severe drought events in the study region. For example, 2014-2015, 2009-2010, 1994-1995 and 1983-1984 were some of the historic drought years in the country. The temporal assessment of the meteorological drought indicated the occurrence of those drought years with different severity levels. For example, severe to extreme drought conditions were observed in 2014-2015 in all stations except Assossa with drought intensity ranging from -1.52 to -3.28 . The minimum intensity was indicated at Debremarkos station (-3.28). In general, the stations located in the eastern, southern and northern parts of the basin indicated more substantial drought than the stations located in the western part. Relatively persistent droughts have been observed in the years 2014-2015 and 1994-1995. Figure 6 further shows the trend of the frequency of occurrence of drought in the region. Although the trends were statistically insignificant, a relatively strong trend of increasing frequency was observed in the six stations during this season. Regular monitoring of this increasing trend is therefore recommended since Kiremt is the main rainy season in the basin on which agricultural production is highly reliant. The temporal assessment results obtained in this study are in line with the previous findings (e.g., study [8]). Hence, 
CHIRPS rainfall can be used as an alternative source of information in developing drought monitoring and early warning systems for the basin.
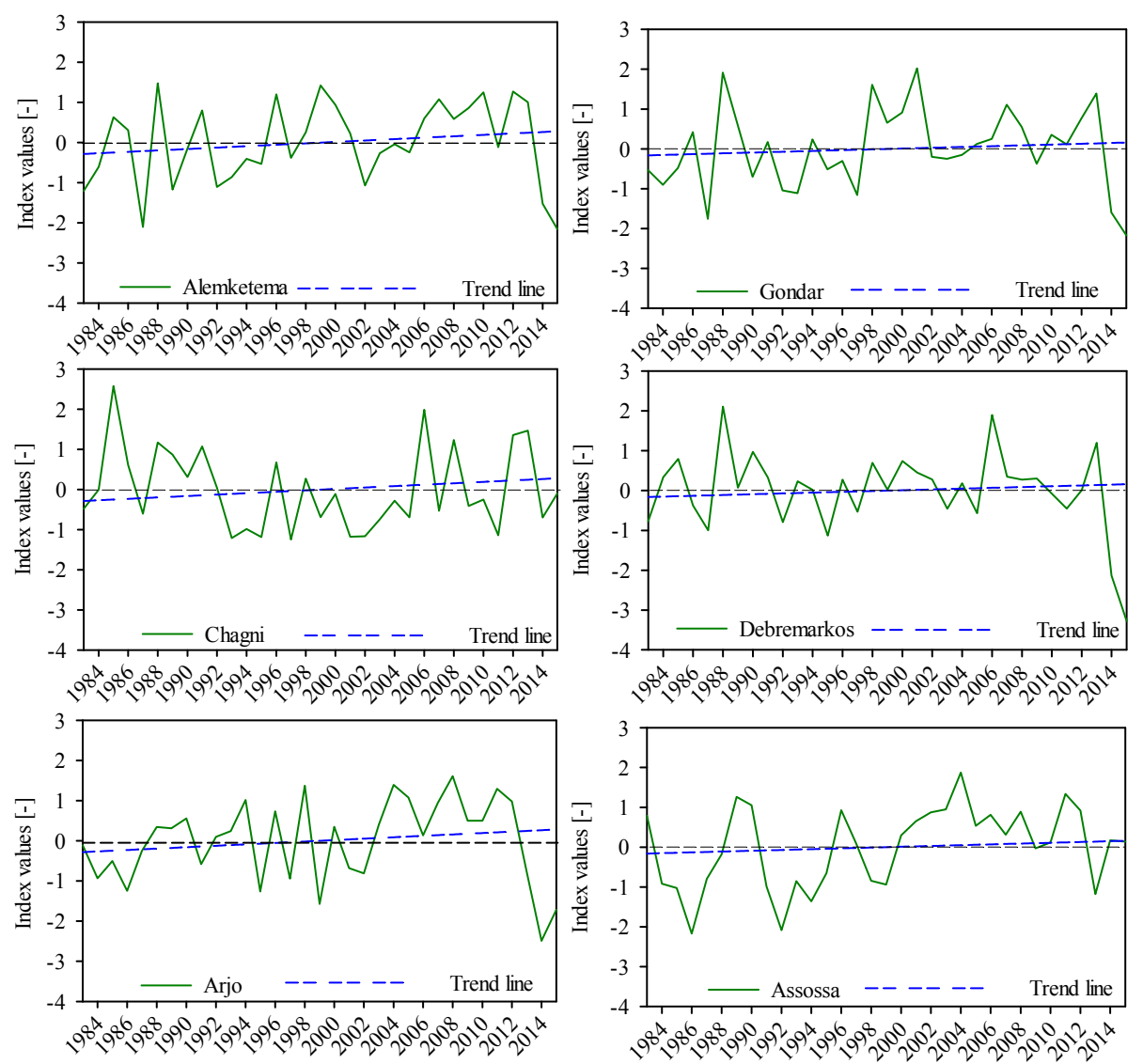

Figure 6. Time series plots of 3-month Climate Hazards Group InfraRed Precipitation with Stations (CHIRPS) Z-Score at six selected weather stations for 1983-2015.

\subsubsection{Spatial Drought Assessment}

The spatial patterns of meteorological drought over the basin were studied within the study period; however, two recent drought years (2009 and 2015) and one non-drought year (2006) were selected for further demonstration and discussion in this section (Figure 7). According to the news agencies, the 2015 drought was reported as one of the most severe recent droughts in the country, and it extended into 2016 in some parts of the country (http:/ / www.unocha.org/el-nino-east-africa; [6]). A United Nations report indicated that about 8.2 million people needed emergency food aid, as reported by the Aljazeera news agency in November 2015 (http:/ / www.aljazeera.com/news/2015/ 11/ethiopia-hit-worst-drought-decades-151112154747151.html). Figure 7 shows the spatial extents of drought during the main rainy season (June, July, August and September) in the basin. The severity of the 2009 and 2015 droughts are indicated by their spatial extent. Extreme drought was observed in the majority of the basin during these years. For example, the central, eastern, northern and northeastern parts were affected by extreme drought in 2015 whereas severe drought was observed in central, eastern and northwestern parts in 2009. The year 2006 was also indicated as a non-drought year since all parts except some pockets (mild drought) were shown as non-drought condition. The spatial extents of other historic drought years were also indicated by the index (not shown). In general, the index clearly indicated the drought and wet years in the basin. Hence, the CHIRPS precipitation product can be used to study the spatial assessment of drought and to develop the drought monitoring and early warning system in the basin. 

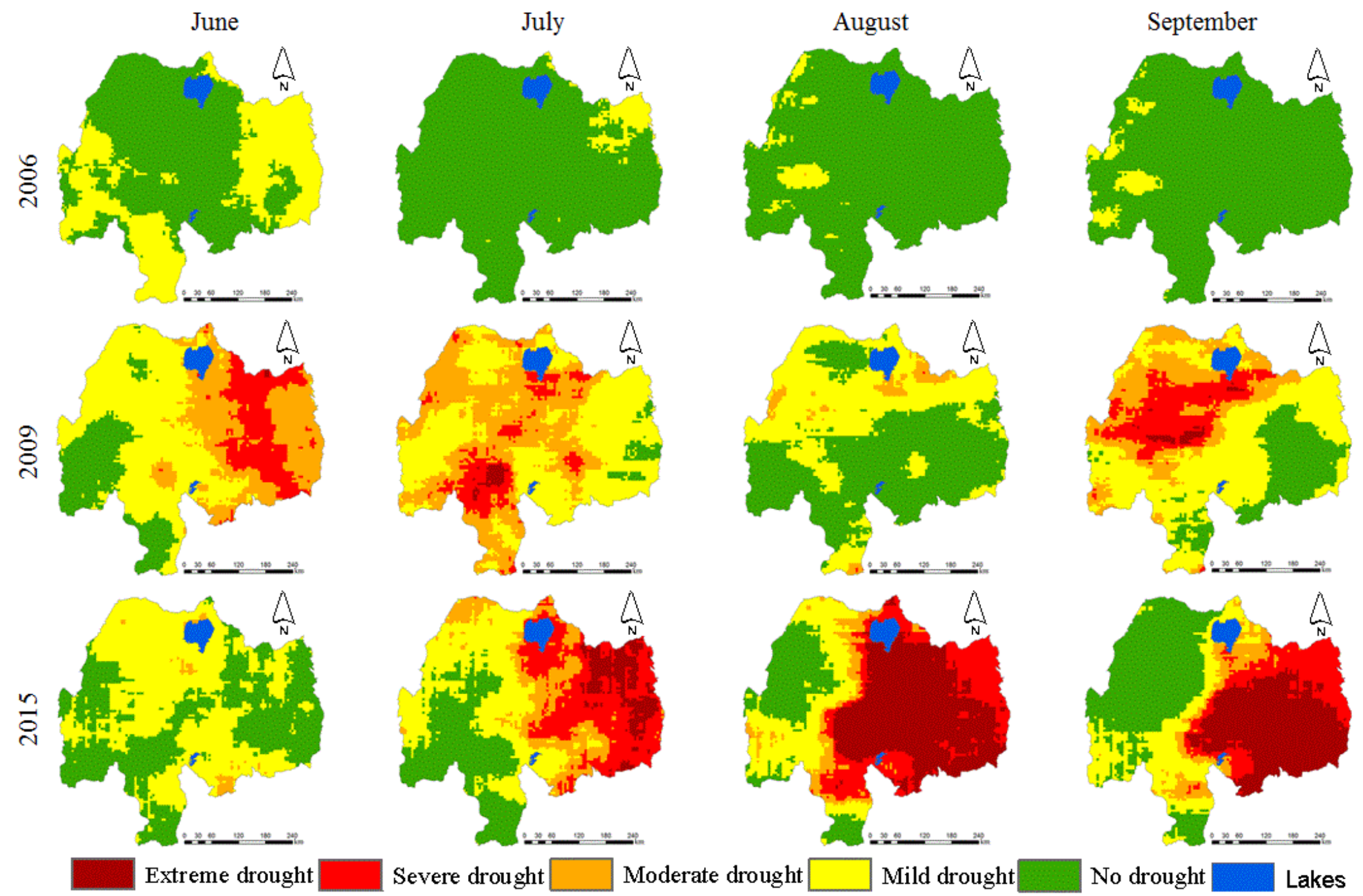

Figure 7. The spatial extents of meteorological drought during recent drought years (2009 and 2015) and a non-drought year (2006). 


\section{Summary and Conclusions}

The availability of satellite-derived rainfall products at local and global scales has proved to be beneficial in filling the data gap, particularly in developing countries that have data scarcity. However, evaluating these rainfall products is essential for any application that includes studying drought and water resources problems. In this study, the performances of five satellite rainfall products (CHIRPS, PERSIANN, TARCAT, TMPA and ARC 2.0) were first investigated by comparing them with gauged rainfall data from ten independent weather stations across the UBN basin. The statistical approach was used for the performance evaluation at multiple time scales (i.e., dekadal, monthly and seasonal time scales). The evaluation process was undertaken to identify the best satellite rainfall product for spatial and temporal assessment of meteorological drought in the basin. After analyzing the results, the following conclusions were drawn.

In general, the performance of the five satellite rainfall products were reasonably good in detecting the occurrence of rainfall and in estimating the amount of dekadal, monthly and seasonal rainfall in the basin. Comparison of the five-satellite rainfall products have shown that CHIRPS and TARCAT are the best products, whereas PERSSIAN exhibited the poorest performance when evaluated in all statistical measures considered in this study at the dekadal time scale. This shows that both CHIRPS and TARCAT products can be used to develop operational drought or flood monitoring and early warning system since dekadal time scale better identify periods of low or heavy rainfall events in the study area. Even though TMPA showed an average performance on other criteria, it scored the perfect bias that shows its performance to capture the total volume of dekadal rainfall. Hence, TMPA can be used in the water resource applications that involve the potential use of the total volume of rainfall. ARC showed an average performance under all the evaluation criteria.

The performances of all the satellite rainfall products were increased as the aggregation period increases. CHIRPS performed very well under all the evaluation criteria considered during the monthly and seasonal time scales. Relatively higher correlation coefficients $(r>0.80)$ and mean Bias (0.98) were scored when the CHIRPS rainfall product was compared with gauged rainfall on monthly time scale. In addition, CHIRPS scored the best ME and RMSE in 50\% and $80 \%$ of the total validation weather stations. TARCAT scored the next highest performance whereas PERSIANN showed relatively weak performance. In general, the CHIRPS rainfall product outperformed the other four satellite-derived rainfall products at monthly and seasonal time scales. Thus, CHIRPS rainfall was selected and used for further application to study the spatial and temporal patterns of meteorological drought in the UBN basin. The good performance of CHIRPS and TARCAT may depend on the reduced effect of pixel-to-point comparison associated with the smaller the grid size. Moreover, the number of the ground observation stations data used in each satellite rainfall product may have a great contribution in terms of reducing the errors induced due to the orographic effect of rainfall in the highlands in the case of the UBN basin.

The temporal assessment of meteorological drought showed the occurrence of mild to severe historic drought events in the UBN basin. The severity of the known drought years, such as 2014-2015, 2009-2010, 1994-1995 and 1983-1984, was indicated in more than 50\% of the weather stations. The spatial assessment of drought in the UBN basin also showed the occurrence of the extreme drought event that covered mainly the central, eastern and southeastern parts of the basin. The 2015 drought was remarkable and clearly indicated in the drought-prone region of the UBN basin (i.e., eastern and northeastern parts). Generally, the results indicated that the CHIRPS rainfall product could be used as an alternative source of information to develop the drought monitoring tools for an early warning system that could help in making better decisions in the UBN basin.

Acknowledgments: This research was financially supported by NASA Project NNX14AD30G. We are also indebted to the National Meteorological Agency (NMA) of Ethiopia for providing the long-term climate data. We acknowledge Deborah Wood of the National Drought Mitigation Center for her editorial comments.

Author Contributions: Yared Bayissa and Tsegaye Tadesse frame the research, analyzed the result and prepared the draft version of the manuscript. Getachew Demisse and Andualem Shiferaw involved on data collection and 
pre-processing. All the authors contributed on reviewing and commenting on the result and conclusion sections of the manuscript.

Conflicts of Interest: The authors declare no conflict of interest.

\section{References}

1. Sheffield, J.; Wood, F. Drought: Past Problems and Future Scenarios; Earthscan: London, UK, 2012.

2. Wheaton, E.; Kulshreshtha, S.; Wittrock, V.; Koshida, G. Dry Times: Hard Lessons from the Canadian Drought of 2001 and 2002. Can. Geogr. 2008, 52, 241-262. [CrossRef]

3. Zhang, A.; Jia, G. Monitoring Meteorological Drought in Semiarid Regions Using Multi-Sensor Microwave Remote Sensing Data. Remote Sens. Environ. 2013, 134, 12-23. [CrossRef]

4. Mishra, A.K.; Singh, V.P. A review of drought concepts. J. Hydrol. 2009, 391, 202-216. [CrossRef]

5. Edossa, D.; Babel, S.; Gupta, D. Drought analysis in the Awash River Basin, Ethiopia. Water Resour. Manag. 2009, 24, 1441-1460. [CrossRef]

6. Viste, E.; Korecha, D.; Sorteberg, A. Recent drought and precipitation tendencies in Ethiopia. Theor. Appl. Climatol. 2013, 112, 535-551. [CrossRef]

7. Tagel, G.; Van Der Veen, A.; Maathuis, B. Spatial and temporal assessment of drought in the Northern highlands of Ethiopia. Int. J. Appl. Earth Obs. Geoinf. 2011, 13, 309-321.

8. Bayissa, Y.; Semu, A.; Yunqing, X.; Schalk, J.A.; Shreedhar, M.; Dimitri, P.S.; van Griensven, A.; Tadesse, T. Spatio-temporal assessment of meteorological drought under the influence of varying record length: The case of Upper Blue Nile Basin, Ethiopia. Hydrol. Sci. J. 2015, 60, 1927-1942. [CrossRef]

9. Guha-Sapir, D.; Vos, F.; Below, R.; Ponserre, S. Annual Disaster Statistical Review 2010: The Numbers and Trends; Université Catholique de Louvain: Brussels, Belgium, 2011.

10. CSA. Statistical Abstract; FDRE/CSA; Central Statistical Authority: Addis Ababa, Ethiopia, 1999.

11. Melesse, T.; Hoogmoed, W.B.; Rockström, J.; Savenije, H. Conservation tillage implements and systems for smallholder farmers in semi-arid Ethiopia. Soil Tillage Res. 2009, 104, 185-191.

12. Bewket, W.; Conway, D. A note on the temporal and spatial variability of rainfall in the drought-prone Amhara region of Ethiopia. Int. J. Climatol. 2007, 27, 1467-1477. [CrossRef]

13. Seleshi, Y.; Zanke, U. Recent change in rainfall and rainy days in Ethiopia. Int. J. Climatol. 2004, $24,973-983$. [CrossRef]

14. Trambauer, P.; Maskey, S.; Werner, M.; Pappenberger, F.; Van Beek, L.; Uhlenbrook, S. Identification and simulation of space-time variability of past hydrological drought events in the Limpopo River Basin, Southern Africa. Hydrol. Earth Syst. Sci. Discuss. 2014, 11, 2639-2677. [CrossRef]

15. Barua, S.; Ng, M.; Perera, C. Comparative evaluation of drought indexes: Case study on the Yarra River catchment in Australia. J. Water Resour. Plan. Manag. 2011, 37, 215-226. [CrossRef]

16. Wilhite, D.A. Drought as a Natural Hazard: Concepts and Definitions. In Drought: A Global Assessment; Wilhite, D.A., Ed.; Routledge: London, UK, 2000; Volume 1, pp. 3-18.

17. Narasimhan, B.; Srinivasan, R. Development and evaluation of Soil Moisture Deficit Index (SMDI) and Evapotranspiration Deficit Index (ETDI) for agricultural drought monitoring. Agric. For. Meteorol. 2005, 133, 69-88. [CrossRef]

18. Valliyodan, B.; Nguyen, H.T. Understanding regulatory networks and engineering for enhanced drought tolerance in plants. Curr. Opin. Plant Biol. 2006, 9, 189-195. [CrossRef] [PubMed]

19. Wilhite, D.; Buchanan-Smith, M. Drought as Hazard: Understanding the Natural and Social Context. In Drought and Water Crises: Science, Technology, and Management Issues; Wilhite, D.A., Ed.; CRC Press: Boca Raton, FL, USA, 2005; pp. 3-29.

20. Sepulcre-Canto, G.; Horion, S.; Singleton, A.; Carrao, H.; Vogt, J. Development of a Combined Drought Indicator to detect agricultural drought in Europe. Nat. Hazards Earth Syst. Sci. 2012, 12, 3519-3531. [CrossRef]

21. Beyene, E.; Meissner, B. Spatio-temporal analyses of correlation between NOAA satellite RFE and weather stations' rainfall record in Ethiopia. Int. J. Appl. Earth Obs. Geoinf. 2010, 12, S69-S75. [CrossRef]

22. Korecha, D.; Barnston, A. Predictability of June-September Rainfall in Ethiopia. Mon. Weather Rev. 2007, 135, 628-650. [CrossRef] 
23. Hirpa, F.; Gebremichael, M.; Hopson, T. Evaluation of High-Resolution Satellite Precipitation Products over Very Complex Terrain in Ethiopia. J. Appl. Meteorol. Climatol. 2010, 49, 1044-1051. [CrossRef]

24. Tadesse, T.; Senay, G.; Berhan, G.; Regassa, T.; Beyene, S. Evaluating A Satellite-Based Seasonal Evapotranspiration Product and Identifying Its Relationship with Other Satellite-Derived Products and Crop Yield: A Case Study for Ethiopia. J. Appl. Meteorol. Climatol. 2015, 40, 39-54. [CrossRef]

25. Dinku, T.; Chidzambwa, S.; Ceccato, P.; Connor, S.; Ropelewski, C. Validation of high-resolution satellite rainfall products over complex terrain. Int. J. Remote Sens. 2008, 29, 4097-4110. [CrossRef]

26. Romilly, T.; Gebremichael, M. Evaluation of satellite rainfall estimates over Ethiopian river basins. Hydrol. Earth Syst. Sci. 2011, 15, 1505-1514. [CrossRef]

27. Bitew, M.; Gebremichael, M.; Ghebremichael, L.; Bayissa, Y. Evaluation of High-Resolution Satellite Rainfall Products through Streamflow Simulation in a Hydrological Modeling of a Small Mountainous Watershed in Ethiopia. J. Hydrometeorol. 2012, 13, 338-350. [CrossRef]

28. Bitew, M.; Gebremichael, M. Evaluation of satellite rainfall products through hydrologic simulation in a fully distributed hydrologic model. Water Resour. Res. 2011, 47, W06526. [CrossRef]

29. Sorooshian, S.; Hsu, K.; Gao, X.; Gupta, H.; Imam, B.; Braithwaite, D. Evaluation of PERSIANN System Satellite-Based Estimates of Tropical Rainfall. Bull. Am. Meteorol. Soc. 2000, 81, 2035-2046. [CrossRef]

30. Qin, Y.; Chen, Z.; Shen, Y.; Zhang, S.; Shi, R. Evaluation of Satellite Rainfall Estimates over the Chinese Mainland. Remote Sens. 2014, 6, 11649-11672. [CrossRef]

31. Moctar, D.; Sander, J. Evaluation and comparison of satellite-based rainfall products in Burkina Faso, West Africa. Int. J. Remote Sens. 2016, 37, 3995-4014.

32. Toté, C.; Patricio, D.; Boogaard, H.; Wijngaart, R.; Tarnavsky, E.; Funk, C. Evaluation of Satellite Rainfall Estimates for Drought and Flood Monitoring in Mozambique. Remote Sens. 2015, 7, 1758-1776. [CrossRef]

33. Yilma, A.; Awulachew, S. Characterization and Atlas of the Blue Nile Basin and Its Sub Basins; International Water Management Institute (IWMI): Colombo, Sri Lanka, 2009.

34. Conway, D. The climate and hydrology of the Upper Blue Nile River. Geogr. J. 2000, 166, 49-62. [CrossRef]

35. Kebede, S.; Travi, Y.; Alemayehu, T.; Marc, V. Water balance of Lake Tana and its sensitivity to fluctuations in rainfall, Blue Nile basin, Ethiopia. J. Hydrol. 2006, 316, 233-247. [CrossRef]

36. Mellander, P.; Gebrehiwot, S.; Gärdenäs, A.; Bewket, W.; Bishop, K. Summer rains and dry seasons in the Upper Blue Nile Basin: the predictability of half a century of past and future spatiotemporal patterns. PLOS ONE 2013, 8, e68461. [CrossRef] [PubMed]

37. Saha, S.; Moorthi, S.; Pan, H.; Wu, X.; Wang, J.; Nadiga, S.; Tripp, P.; Kistler, R.; Woollen, J.; Behringer, D. The NCEP climate forecast system reanalysis. Bull. Am. Meteorol. Soc. 2010, 1, 1-146. [CrossRef]

38. Funk, C.; Peterson, P.; Landsfeld, M.; Pedreros, D.; Verdin, J.; Rowland, J.; Romero, B.; Husak, G.; Michaelsen, J.; Verdin, A.; et al. A Quasi-Global Precipitation Time Series for Drought Monitoring. Available online: pubs.usgs.gov/ds/832/ (accessed on 20 February 2017).

39. Maidment, R.; Grimes, D.; Allan, R.; Tarnavsky, E.; Stringer, M.; Hewison, T.; Roebeling, R.; Black, E. The 30 year TAMSAT African Rainfall Climatology And Time series (TARCAT) data set. J. Geophys. Res. 2014. [CrossRef]

40. Tarnavsky, E.; Grimes, D.; Maidment, R.; Black, E.; Allan, R.; Stringer, M.; Chadwick, R.; Kayitakire, F. Extension of the TAMSAT Satellite-based Rainfall Monitoring over Africa and from 1983 to present. J. Appl. Meteorol. Climatol. 2014. [CrossRef]

41. Novella, N.; Thiaw, W. African rainfall climatology version 2 for famine early warning systems. J. Appl. Meteorol. Climatol. 2013, 52, 588-606. [CrossRef]

42. Ashouri, H.; Hsu, K.; Sorooshian, S.; Braithwaite, D.; Knapp, K.; Cecil, L.; Nelson, B.; Prat, O. PERSIANN-CDR: Daily Precipitation Climate Data Record from Multisatellite Observations for Hydrological and Climate Studies. Bull. Am. Meteorol. Soc. 2015, 96, 69-83. [CrossRef]

43. Hsu, K.; Gao, X.; Sorooshian, S.; Gupta, H. Precipitation Estimation from Remotely Sensed Information Using Artificial Neural Networks. J. Appl. Meteorol. 1997, 36, 1176-1190. [CrossRef]

44. Hsu, K.; Gupta, H.; Gao, X.; Sorooshian, S. Estimation of Physical Variables from Multiple Channel Remotely Sensed Imagery Using a Neural Network: Application to Rainfall Estimation. Water Resour. Res. 1999, 35, 1605-1618. [CrossRef] 
45. Hsu, K.; Gupta, H.; Gao, X.; Sorooshian, S. Rainfall Estimation from Satellite Imagery. In Artificial Neural Networks in Hydrology; Govindaraju, R.S., Rao, A.R., Eds.; Kluwer Academic Publishers: Dordrecht, The Netherlands, 2000; Chapter 11; pp. 209-234.

46. Sorooshian, S.; Gao, X.; Hsu, K.; Maddox, R.; Hong, Y.; Imam, B.; Gupta, H. Diurnal Variability of Tropical Rainfall Retrived from Combined GOES and TRMM Satellite Information. J. Clim. 2002, 15, 983-1001. [CrossRef]

47. Sorooshian, S.; Nguyen, P.; Sellars, S.; Braithwaite, D.; AghaKouchak, A.; Hsu, K. Satellite-Based Remote Sensing Estimation of Precipitation for Early Warning Systems, Extreme Natural Hazards, Disaster Risks and Societal Implications; Ismail-Zadeh, A., Fucugauchi, J.U., Kijko, A., Takeuchi, K., Zaliapin, I., Eds.; Cambridge University Press: Cambridge, UK, 2014; pp. 99-111.

48. Huffman, G.; Bolvin, D. TRMM and Other Data Precipitation Data Set Documentation. 2013. Available online: ftp://meso-a.gsfc.nasa.gov/pub/trmmdocs/3B42_3B43_doc.pdf (accessed on 18 February 2017).

49. McKee, T.; Doesken, N.; Kleist, J. The relationship of drought frequency and duration to time scales. In Proceedings of the 8th Conference of Applied Climatology, Anaheim, CA, USA, 17-22 January 1993; Meterological Society: Boston, MA, USA; pp. 179-184.

50. Khadr, M. Temporal and spatial analysis of meteorological drought characteristics in the upper Blue Nile river region. Hydrol. Res. 2017, 48, 265-276. [CrossRef]

(C) 2017 by the authors. Licensee MDPI, Basel, Switzerland. This article is an open access article distributed under the terms and conditions of the Creative Commons Attribution (CC BY) license (http://creativecommons.org/licenses/by/4.0/). 